\title{
Developing Pavement Distress Deterioration Models for Pavement Management System Using Markovian Probabilistic Process
}

\author{
Promothes Saha, ${ }^{1}$ Khaled Ksaibati, ${ }^{1}$ and Rebecca Atadero ${ }^{2}$ \\ ${ }^{1}$ Department of Civil and Architectural Engineering, University of Wyoming, Dept. 3295, 1000 E. University Ave, Laramie, \\ WY 82071, USA \\ ${ }^{2}$ Department of Civil and Environmental Engineering, Colorado State University, Fort Collins, CO 80523-1372, USA \\ Correspondence should be addressed to Promothes Saha; psaha@uwyo.edu
}

Received 1 August 2017; Revised 25 September 2017; Accepted 1 October 2017; Published 19 November 2017

Academic Editor: Ghassan Chehab

Copyright (C) 2017 Promothes Saha et al. This is an open access article distributed under the Creative Commons Attribution License, which permits unrestricted use, distribution, and reproduction in any medium, provided the original work is properly cited.

\begin{abstract}
In the state of Colorado, the Colorado Department of Transportation (CDOT) utilizes their pavement management system (PMS) to manage approximately 9,100 miles of interstate, highways, and low-volume roads. Three types of deterioration models are currently being used in the existing PMS: site-specific, family, and expert opinion curves. These curves are developed using deterministic techniques. In the deterministic technique, the uncertainties of pavement deterioration related to traffic and weather are not considered. Probabilistic models that take into account the uncertainties result in more accurate curves. In this study, probabilistic models using the discrete-time Markov process were developed for five distress indices: transverse, longitudinal, fatigue, rut, and ride indices, as a case study on low-volume roads. Regression techniques were used to develop the deterioration paths using the predicted distribution of indices estimated from the Markov process. Results indicated that longitudinal, fatigue, and rut indices had very slow deterioration over time, whereas transverse and ride indices showed faster deterioration. The developed deterioration models had the coefficient of determination $\left(R^{2}\right)$ above 0.84 . As probabilistic models provide more accurate results, it is recommended that these models be used as the family curves in the CDOT PMS for low-volume roads.
\end{abstract}

\section{Introduction}

The Colorado Department of Transportation (CDOT) is responsible for maintaining a highway system that encompasses more than 9,100 centerline miles (about 23,000 total lane miles) and includes 3,437 bridges [1]. Every year, approximately $\$ 740$ million is allocated to maintain this system. In order to maintain this system most efficiently, the CDOT uses a pavement management system (PMS). A PMS is a strategic and systematic process to maintain and upgrade the road network. When funding is limited, the PMS identifies the best mix of road preservation projects that provides the most benefit to society in terms of overall lifecycle cost of the road network. In the CDOT PMS, a composite index, known as the overall pavement index (OPI), is used as the reporting criterion for the condition of the state highway system [2]. The OPI comprised a weighted combination of ride quality, rutting, and cracking. There are three different types of cracking: transverse, longitudinal, and fatigue. The CDOT highway maintenance system is divided into four categories: interstate and national highway system (NHS) high volume, medium volume, and low volume based on the annual average daily traffic (AADT) and annual average daily truck traffic (AADTT) [3]. The lowvolume roads consist of 2,022 centerline miles (about total 5,614 lane miles).

As the performance of each roadway segment is different, the CDOT develops a segment-specific deterioration curve. These curves are generated to satisfy certain conditions, including at least five years of historical pavement distress data after last rehabilitation, the standard deviation of the data cannot exceed 10, and the minimum coefficient of regression $\left(R^{2}\right)$ is considered as 0.5 . When these conditions are not met, a segment-specific curve cannot be generated, and the family or expert opinion curves can be used. Family or expert opinion curves are generated for some roadway 
segments with similar traffic, pavement type, and pavement thickness in a same climate area.

All these deterioration curves are generated using a deterministic technique $[3,4]$. The segment-specific performance curves can be generated for a smaller number of segments satisfying the required conditions [4]. Specifically, continuous five-year distress data without any maintenance treatment could be found for some roadway segments. Moreover, the evaluation of distress indices exceeds the standard deviation of 10 for a significant number of roadway segments [4]. However, as the deterministic technique does not take into account the uncertainties in pavement behavior under variable traffic load and weather conditions [5-7], modeling uncertainty requires the use of probabilistic operation research techniques $[5,6]$. Key summaries from the study Butt [8] conducted about implementing a probabilistic technique in the pavement management system (PMS) are as follows:

(i) Predicted maintenance treatments are not fixed, rather depend on how the pavement actually deteriorates.

(ii) Because of the uncertainty in selecting maintenance treatments, the treatments should be selected with a high degree of probability.

(iii) The success of maintenance decisions can be evaluated by comparing the expected and actual proportions of the miles in a given condition state.

(iv) This model has the potential for significant cost saving in selecting projects satisfying the target network performance.

(v) This model can also be incorporated into dynamic programming to produce optimal solutions.

In a probabilistic technique, only two years of historical data are needed to develop a deterioration model. Currently, the Markov process is popular among probabilistic techniques to develop a deterioration model. Michigan DOT already improved their PMS using the Markov process $[5,9]$. In this paper, the Markov process was applied to the low-volume roads of Colorado to develop deterioration models. These deterioration models can be used to replace the family curves CDOT currently uses for their PMS.

\section{CDOT Pavement Deterioration Model}

The CDOT pavement management software uses five distress indices to model pavement deterioration: three cracking indices (transverse, longitudinal, and fatigue), roughness, and rutting indices. When all the values are loaded into the software, it generates deterioration curves for all roadway segments. For each segment, five performance curves are generated for each of the distress indices. These performance curves are named as the site-specific curves. There are two other types of performance curves: pavement family and expert opinion. The most desirable of these is the site-specific curve. When site-specific curves are not available, family or expert opinion curves can be used.
2.1. Site-Specific Curves. The length of the CDOT roadway segments ranges from 0.5 mile to 5 miles. For each segment, a site-specific performance curve is generated using historical distress data as discussed earlier.

2.2. Family of Curves. The CDOT uses the following criteria to define the family curve:

(i) Pavement types: asphalt, asphalt over concrete, concrete, and concrete over asphalt

(ii) Traffic: low, medium, high, very high, and very very high

(iii) Climate: very cold, cold, moderate, and hot

(iv) Pavement thickness (asphalt: 0 to 4 inches, 4 to 6 inches, and greater than 6 inches; concrete: pavements less than 8 inches and greater than 8 inches)

These categories allow for 200 pavement families. At least 9 points are needed to generate a family curve.

2.3. Expert Opinion Curves. When neither site-specific nor family curves are available, an expert opinion curve is assigned. The expert opinion curves are generated for each pavement family. As there were 200 pavement families, 200 curves were generated. These curves were not developed from regression analysis of data, rather are derived from expert opinion. These curves are least desirable for any pavement segment [4].

\section{Literature Review}

In the PMS, the pavement deterioration model (PDM) is the key to making maintenance strategies and allocating funding for the future. An accurate and reliable PDM is essential for the optimization model of the PMS [10]. Many researchers have attempted to develop a PDM using different techniques $[5,6,8,9,11,12]$. These techniques can be divided into two main types-namely, deterministic and probabilistic models.

3.1. Deterministic Pavement Deterioration Model. Deterministic modeling techniques are the most common because of their relative simplicity, ease of use, and familiarity $[5,6]$. These techniques include straight-line extrapolation, S-shaped curves, polynomial constrained least squares, and logistic growth models [13]. Silva et al. [5] discussed the advantages and disadvantages of the deterministic models. The disadvantages are as follows:

(i) Models do not take into account the uncertainties in pavement behavior under variable traffic load and weather conditions.

(ii) Developing models require an accurate and abundant dataset. Accuracy of datasets can be greatly affected by regular maintenance or minor rehabilitation activities.

(iii) It is necessary to include all confounding variables that affect pavement deterioration. 
The critical disadvantage of deterministic models is that it does not take into account the uncertainties [5-7]. Modeling uncertainty requires the use of probabilistic operation research techniques $[5,6]$.

3.2. Probabilistic Pavement Deterioration Model. In the early 1970s, the applications of probabilistic models for modeling pavement performance were first discussed [5]. Among the probabilistic models, the Markov model is currently being implemented in modeling pavement performance. Many research attempted to develop the pavement performance model using the Markov process [5, 6, 8, 14-17]. Surendrakumar et al. [6] used the Markov process to develop a decision support system for pavement maintenance management. In this study, a Poisson distribution has been used in developing state transition matrices. Butt [8] studied the advantages of using a Markov process in the pavement management system (PMS). A critical component of the Markov model is the transition probability matrix (TPM). Generally, the TPM is calculated based on the historical pavement condition data [15]. The Markov process can be defined in a discrete or continuous time with a countable state space. In order to explain a discrete-time Markov process, consider a road for which the condition is observed at year $0,1,2, \ldots, n$. Let $X_{n}$ be the condition at year $n$ for $n=0,1,2, \ldots X_{n}$ can be denoted as the state of the process at time $n$, with $X_{0}$ denoting the initial state. If $X_{n}$ takes values in a discrete space such as $Z=\{1,2, \ldots, 100\}$, then the process is said to be discrete-valued.

3.3. Formulation of the Distress Indices. According to the CDOT, the distress indices are scaled from 0 to 100 , where 100 represents a flawless pavement with no distresses and 0 represents the worst condition. Transverse, longitudinal, and fatigue cracking indices can be calculated for each roadway segment using (1), while roughness and rut indices can be calculated with (2) and (3), respectively.

$$
\begin{gathered}
\text { Distress index }=100\left(1-\frac{\text { Distress }_{\mathrm{LOW}}}{\operatorname{Max}_{\mathrm{LOW}}}-\frac{\text { Distress }_{\mathrm{MID}}}{\operatorname{Max}_{\mathrm{MID}}}\right. \\
\left.-\frac{\text { Distress }_{\mathrm{HIGH}}}{\mathrm{Max}_{\mathrm{HIGH}}}\right) \\
\text { Ride index }=100 *\left(1-\frac{\mathrm{IRI}_{\mathrm{avg}}-A_{\mathrm{min}}}{B_{\mathrm{max}}}\right) \\
\text { Rut index }=100 *\left(1-\frac{\mathrm{Rut}_{\mathrm{avg}}-B_{\min }}{B_{\mathrm{max}}-B_{\min }}\right)
\end{gathered}
$$

where (i) Distress LOW $_{\text {, Distress }}$ MID, and Distress HIGH $_{\text {are }}$ low, median, and high values of fatigue, transverse, and longitudinal cracking, respectively, and (ii) $\mathrm{IRI}_{\mathrm{avg}}$ and Rut are average IRI and rut depth, respectively.

The values of all other parameters in (1)-(3) can be found in Table 1.
TABLE 1: The values of parameters for calculating distress indices for asphalt pavement.

\begin{tabular}{lccccc}
\hline & $\begin{array}{c}\text { Fatigue } \\
\text { index }\end{array}$ & $\begin{array}{c}\text { Transverse } \\
\text { index }\end{array}$ & $\begin{array}{c}\text { Longitudinal } \\
\text { index }\end{array}$ & $\begin{array}{c}\text { Ride } \\
\text { index }\end{array}$ & $\begin{array}{c}\text { Rut } \\
\text { index }\end{array}$ \\
\hline $\operatorname{Max}_{\text {LOW }}$ & 6230 & 160 & 3802 & - & - \\
$\operatorname{Max}_{\text {MID }}$ & 3375 & 111 & 2492 & - & - \\
$\operatorname{Max}_{\text {HIGH }}$ & 2014 & 49 & 1478 & - & - \\
$A_{\min }$ & - & - & - & 0 & - \\
$B_{\min }$ & - & - & - & - & 0.15 \\
$B_{\max }$ & - & - & - & 26 & 0.95 \\
\hline
\end{tabular}

TABle 2: Transition probability matrix with five states [7].

\begin{tabular}{lcccccc}
\hline To condition & & 5 & 4 & 3 & 2 & 1 \\
\hline & 5 & $p(1)$ & $1-p(1)$ & 0 & 0 & 0 \\
& 4 & 0 & $p(2)$ & $1-p(2)$ & 0 & 0 \\
From condition & 3 & 0 & 0 & $p(3)$ & $1-p(3)$ & 0 \\
& 2 & 0 & 0 & 0 & $p(4)$ & $1-p(4)$ \\
& 1 & 0 & 0 & 0 & 0 & 1 \\
\hline
\end{tabular}

\section{Methodology}

The Markov model provides a prediction of pavement performance. Pavement performance can be determined by each distress index or a combined index representing the overall pavement condition. Most commonly used pavement distress indices are transverse, fatigue, longitudinal cracking, roughness, and ride. Usually, these indices range from 0 to 100 , where 100 represents the best condition and 0 is for the worst condition. A pavement section begins its life in a near-perfect condition. Over the years, the pavement condition deteriorates due to many factors such as traffic loading and weather conditions. Most states evaluate their pavement condition once a year. In order to develop a capital improvement plan (usually a five-year plan), state agencies need to predict their pavement condition for the next five years. In this section, how to predict the pavement condition for the future using the Markov model is discussed.

Markov models start with developing a transition probability matrix (TPM). A TPM represents the probability that a segment will stay in a specific condition for a specific year. For example, Table 2 represents a TPM of a roadway network $[6,7,18]$. It was assumed that the pavement condition ranges from 1 to 5 , where 5 represents the best condition and 1 is for the worst. In this table, $p(j)$ is the probability that a segment will stay in condition $j(j=1,2, \ldots, 5), p(j)$ is calculated by the number of miles at condition $j$ divided by the total number of miles at conditions $j$ and $j-1$. The entry 1 in the last row of the table indicates a reconstruction state. The pavement condition cannot transit from this state at all. In this table, it was assumed that a segment cannot degrade by more than a single condition in one year. The reason is, from the previous experience it was found that pavement does not degrade that fast.

The next year's pavement condition can be determined by multiplying the initial state vector $v(0)$ by the TPM 
raised to the power of $t$, where $t$ represents the number of years in the future for which the pavement condition will be determined. This initial state vector $v(0)$ considers that all the segments stay at the best condition (condition 5). In this study, as the Markov chain is reserved for a process with a discrete set of times, it can be considered as a discrete-time Markov model. For this example, the initial vector is stated below:

$\begin{array}{llllll}5 & 5 & 4 & 3 & 2 & 1 \\ 5 & 1 & 0 & 0 & 0 & 0\end{array}$

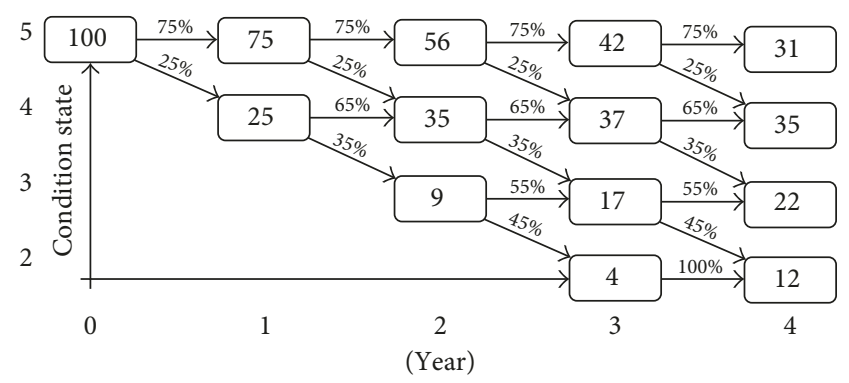

Figure 1: Example of a Markovian deterioration model.

TABLE 3: Maintenance records of low-volume roads in 2014.

\begin{tabular}{|c|c|c|c|c|c|c|c|c|c|}
\hline Route & Beg. MP & End. MP & Rehab. year & Ride index & Rut index & Fatigue index & Transverse index & Longitudinal index & Year \\
\hline $005 \mathrm{~A}$ & 0 & 14.894 & 1994 & 42 & 99 & 93 & 70 & 99 & 2014 \\
\hline $006 \mathrm{~A}$ & 11.825 & 13.867 & 1985 & 73 & 98 & 73 & 61 & 96 & 2014 \\
\hline $006 \mathrm{~A}$ & 11.179 & 11.825 & 1985 & 73 & 98 & 73 & 61 & 96 & 2014 \\
\hline $006 \mathrm{~A}$ & 11.08 & 11.179 & 1985 & 73 & 98 & 73 & 61 & 96 & 2014 \\
\hline
\end{tabular}

The next year's pavement condition can be determined using the following equation:

$$
\begin{gathered}
{[v(1)]=[v(0)] *[\mathrm{TPM}],} \\
{[v(2)]=[v(0)] *[\mathrm{TPM}]^{2},} \\
\vdots \\
{[v(t)]=[v(0)] *[\mathrm{TPM}]^{t} .}
\end{gathered}
$$

Figure 1 provides an example of probability distribution values using the Markov process. Here, a pavement deterioration is modeled for 4 years. At year 0 , a total of 100 miles of the roadway segments stay at condition 5 . From the historical dataset, it was found that $25 \%$ of these miles deteriorated to the next state and the remaining $75 \%$ stayed at the same condition. Similarly, $65 \%$ of the miles that stayed at condition 4 deteriorated to the next state and the remaining 35\% stayed at the same condition.

\section{Data Collection}

In order to develop the deterioration models using the Markov process, a case study was conducted on the lowvolume roads in Colorado. A comprehensive maintenance record of low-volume roads was collected from the CDOT. There are 116 low-volume roads in Colorado with 2,022 miles of pavement. These low-volume roads were segmented by the CDOT, and a total of 342 segments were established. The segments begin and end where there are overlays, new construction, or other changes in the pavement. The database contained information related to road identification number, beginning and ending milepost, and the five distress indices (transverse cracking, longitudinal cracking, fatigue cracking, rut, and ride indices). Five years of maintenance records from 2010 to 2014 were used in this study. The research team had to extract, filter, and combine the datasets from 2010 to 2014 to
TABLE 4: Grouping of distress indices.

\begin{tabular}{lccc}
\hline Index range & Group name & Index range & Group name \\
\hline $96-100$ & 100 & $66-70$ & 70 \\
$91-95$ & 95 & $61-65$ & 65 \\
$86-90$ & 90 & $56-60$ & 60 \\
$81-85$ & 85 & $51-55$ & 55 \\
$76-80$ & 80 & $46-50$ & 50 \\
$71-75$ & 75 & $41-45$ & 45 \\
\hline
\end{tabular}

prepare a single database for low-volume roads. A sample database for the year 2014 is shown in Table 3.

In order to implement the Markov process, the values of each distress index were grouped based on Table 4 . As there were no values of distress indices less than 40 , only the groups that contain values greater than 40 were included. Using this category, Table 3 can be modified to Table 5 .

\section{Data Analysis}

This study intends to develop five separate deterioration models for the five distress indices. In order to do this, a summary matrix for each distress has been developed. A sample summary matrix for the transverse cracking index can be seen in Table 6 . The values in this matrix represent the length in miles. Five years of pavement condition data from 2010 to 2014 were used to develop the matrix as shown in Table 6. Between each consecutive year (2010-2011, 20112012, 2012-2013, and 2013-2014), the miles were calculated from each condition state to another and then combined them for all four consecutive years. In this table, it can be seen that pavement conditions of some roadway segments drop the next year by more than a group. Data showing such a drop were not included in this analysis because this kind of drop is not realistic for pavement deterioration. 
TABLE 5: Modified maintenance records of low-volume roads in 2014.

\begin{tabular}{|c|c|c|c|c|c|c|c|c|c|}
\hline Route & Beg. MP & End. MP & Rehab. year & Ride index & Rut index & Fatigue index & Transverse index & Longitudinal index & Year \\
\hline $005 \mathrm{~A}$ & 0 & 14.894 & 1994 & 45 & 100 & 100 & 70 & 100 & 2014 \\
\hline $006 \mathrm{~A}$ & 11.825 & 13.867 & 1985 & 75 & 100 & 75 & 65 & 100 & 2014 \\
\hline $006 \mathrm{~A}$ & 11.179 & 11.825 & 1985 & 75 & 100 & 75 & 65 & 100 & 2014 \\
\hline $006 \mathrm{~A}$ & 11.08 & 11.179 & 1985 & 75 & 100 & 75 & 65 & 100 & 2014 \\
\hline
\end{tabular}

TABLE 6: Summary of the database in centerline miles for the transverse cracking index.

\begin{tabular}{cccccccccccccccc}
\hline & \multicolumn{1}{c}{ c } & \multicolumn{10}{c}{ Transverse cracking index } \\
& & 100 & 95 & 90 & 85 & 80 & 75 & 70 & 65 & 60 & 55 & 50 & 45 & 40 & 35 \\
\hline & 100 & 872 & 511 & 117 & 16 & 52 & 6 & 0 & 3 & 16 & - & - & 2 & - & - \\
& 95 & - & 1018 & 707 & 397 & 238 & 51 & 0 & 2 & 9 & 2 & - & - & - & - \\
& 90 & - & - & 488 & 412 & 197 & 172 & 117 & 33 & 5 & 2 & 10 & 7 & 2 & - \\
& 85 & - & - & - & 438 & 238 & 101 & 92 & 74 & 37 & 8 & 18 & - & 10 & - \\
& 80 & - & - & - & - & 175 & 135 & 71 & 43 & 45 & 12 & 10 & 8 & 4 & 0 \\
Transverse cracking index & 75 & - & - & - & - & - & 20 & 24 & 66 & 35 & 14 & 7 & 5 & 1 & 9 \\
& 70 & - & - & - & - & - & - & 18 & 3 & 7 & 4 & 6 & 19 & 5 & - \\
& 65 & - & - & - & - & - & - & - & 24 & 21 & 8 & - & 2 & - & - \\
& 60 & - & - & - & - & - & - & - & - & - & - & - & 25 & 2 & 1 \\
& 55 & - & - & - & - & - & - & - & - & - & - & - & - & 2 & - \\
& 50 & - & - & - & - & - & - & - & - & - & - & - & - & - & - \\
& 45 & - & - & - & - & - & - & - & - & - & - & - & - & - & 7 \\
& 40 & - & - & - & - & - & - & - & - & - & - & - & - & - & - \\
& 35 & - & - & - & - & - & - & - & - & - & - & - & - & - & - \\
\hline
\end{tabular}

Table 7: Example of the database in centerline miles of the Markov model.

\begin{tabular}{|c|c|c|c|c|c|}
\hline \multirow{2}{*}{ Index ratings (from one year to another) } & \multicolumn{5}{|c|}{ Length, miles } \\
\hline & Trans. & Ride & Long. & Fatigue & Rut \\
\hline 100 to 100 & 872 & 0 & 4063 & 4285 & 7741 \\
\hline 100 to 95 & 511 & 0 & 964 & 559 & 564 \\
\hline 95 to 95 & 1018 & 443 & 340 & 250 & 153 \\
\hline 95 to 90 & 707 & 149 & 55 & 203 & 5 \\
\hline 90 to 90 & 488 & 1670 & 23 & 99 & 42 \\
\hline 90 to 85 & 412 & 472 & 4 & 40 & 3 \\
\hline 85 to 85 & 438 & 2255 & 8 & 55 & 0 \\
\hline 85 to 80 & 238 & 535 & 1 & 37 & 21 \\
\hline 80 to 80 & 175 & 1882 & 0 & 25 & 0 \\
\hline 80 to 75 & 135 & 263 & 0 & 10 & 0 \\
\hline 75 to 75 & 20 & 307 & 0 & 56 & 1 \\
\hline 75 to 70 & 24 & 47 & 0 & 2 & 0 \\
\hline 70 to 70 & 18 & 65 & 0 & 42 & 0 \\
\hline 70 to 65 & 3 & 11 & 0 & 43 & 0 \\
\hline 65 to 65 & 24 & 164 & 0 & 16 & 0 \\
\hline 65 to 60 & 21 & 3 & 0 & 9 & 0 \\
\hline 60 to 60 & 0 & 0 & 0 & 0 & 0 \\
\hline 60 to 55 & 0 & 0 & 0 & 1 & 0 \\
\hline 55 to 55 & 0 & 0 & 0 & 9 & 0 \\
\hline
\end{tabular}

It is important to note that, in this analysis, the roadway segments that show increase of indices because of implemented maintenance were excluded because this also is not realistic to improve the pavement condition without any maintenance. Satisfying all these conditions, a final summary of distress indices can be presented in Table 7 . This table has been used as the input for the Markovian process.

The Markovian process has been implemented on all five distress indices using the data shown in Table 7. A sample analysis has been presented below for the transverse 
Table 8: Probability distribution values from the Markov model for all five indices.

\begin{tabular}{|c|c|c|c|c|c|}
\hline \multicolumn{6}{|c|}{ Transverse cracking index } \\
\hline Index & Year 1 & Year 2 & Year 3 & Year 4 & Year 5 \\
\hline 100 & 0.631 & 0.398 & 0.251 & 0.158 & 0.1 \\
\hline 95 & 0.369 & 0.451 & 0.413 & 0.336 & 0.257 \\
\hline 90 & 0 & 0.151 & 0.267 & 0.314 & 0.308 \\
\hline 85 & 0 & 0 & 0.069 & 0.167 & 0.252 \\
\hline 80 & 0 & 0 & 0 & 0.024 & 0.072 \\
\hline 75 & 0 & 0 & 0 & 0 & 0.011 \\
\hline \multicolumn{6}{|c|}{ Fatigue cracking index } \\
\hline 100 & 0.885 & 0.783 & 0.692 & 0.612 & 0.542 \\
\hline 95 & 0.115 & 0.166 & 0.182 & 0.18 & 0.17 \\
\hline 90 & 0 & 0.052 & 0.111 & 0.16 & 0.195 \\
\hline 85 & 0 & 0 & 0.015 & 0.041 & 0.071 \\
\hline 80 & 0 & 0 & 0 & 0.06 & 0.02 \\
\hline 75 & 0 & 0 & 0 & 0 & 0.002 \\
\hline \multicolumn{6}{|c|}{ Longitudinal cracking index } \\
\hline 100 & 0.82 & 0.673 & 0.552 & 0.453 & 0.372 \\
\hline 95 & 0.18 & 0.311 & 0.405 & 0.469 & 0.51 \\
\hline 90 & 0 & 0.015 & 0.039 & 0.064 & 0.088 \\
\hline 85 & 0 & 0 & 0.004 & 0.01 & 0.016 \\
\hline \multicolumn{6}{|c|}{ Ride quality index } \\
\hline 100 & - & - & - & - & - \\
\hline 95 & - & - & - & - & - \\
\hline 90 & 0.748 & 0.56 & 0.419 & 0.314 & 0.235 \\
\hline 85 & 0.251 & 0.384 & 0.441 & 0.449 & 0.429 \\
\hline 80 & 0 & 0.055 & 0.129 & 0.202 & 0.262 \\
\hline 75 & 0 & 0 & 0.011 & 0.034 & 0.069 \\
\hline 70 & 0 & 0 & 0 & 0.001 & 0.005 \\
\hline \multicolumn{6}{|c|}{ Rut index } \\
\hline 100 & 0.932 & 0.869 & 0.81 & 0.775 & 0.704 \\
\hline 95 & 0.068 & 0.129 & 0.184 & 0.234 & 0.279 \\
\hline 90 & 0 & 0.002 & 0.006 & 0.01 & 0.016 \\
\hline 85 & 0 & 0 & 0 & 0 & 0.001 \\
\hline
\end{tabular}

TABle 9: Transition matrix of the transverse cracking index.

\begin{tabular}{|c|c|c|c|c|c|c|c|c|c|}
\hline & & \multicolumn{8}{|c|}{ Transverse cracking index } \\
\hline & & 100 & 95 & 90 & 85 & 80 & 75 & 70 & 65 \\
\hline \multirow{8}{*}{ Transverse cracking index } & 100 & 872 & 511 & - & - & - & - & - & - \\
\hline & 95 & - & 1018 & 707 & - & - & - & - & - \\
\hline & 90 & - & - & 488 & 412 & - & - & - & - \\
\hline & 85 & - & - & - & 438 & 238 & - & - & - \\
\hline & 80 & - & - & - & - & 175 & 135 & - & - \\
\hline & 75 & - & - & - & - & - & 20 & 24 & - \\
\hline & 70 & - & - & - & - & - & - & 18 & 3 \\
\hline & 65 & - & - & - & - & - & - & - & 24 \\
\hline
\end{tabular}

cracking index followed by summary results of all indices (Table 8). The Markovian process consists of developing three matrices: transition, transition probability, and probability distribution matrices. Table 9 represents the transition matrix of the transverse cracking index. From this table, it can be seen that the number 872 represents the total length in miles that stay the next year at 100 , and 511 miles deteriorate from 100 to 95 . Using this table, the probability has been calculated as shown in Table 10. From this table, 0.631 represents that $63.1 \%$ of total miles stayed at 100 the next 
TABLE 10: Transition probability matrix of the transverse cracking index.

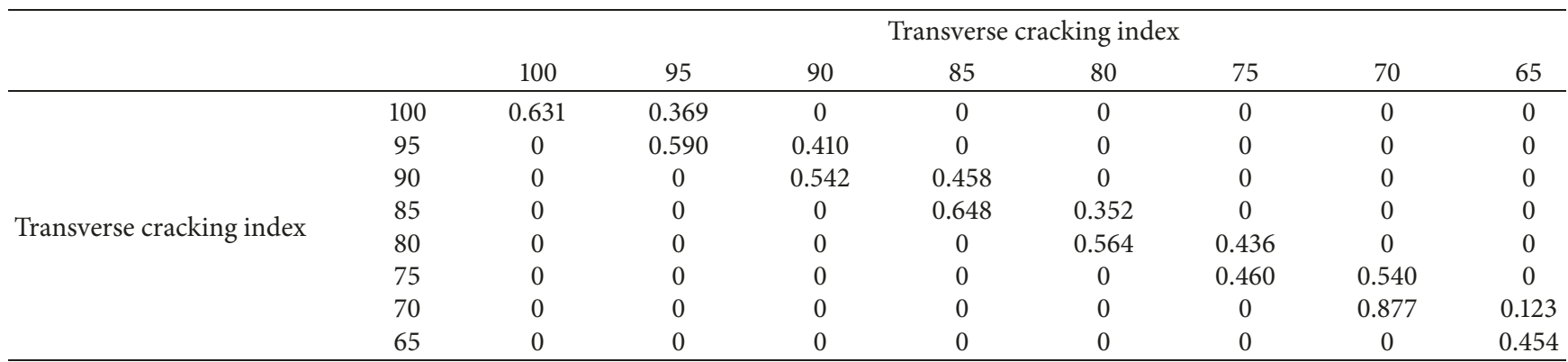

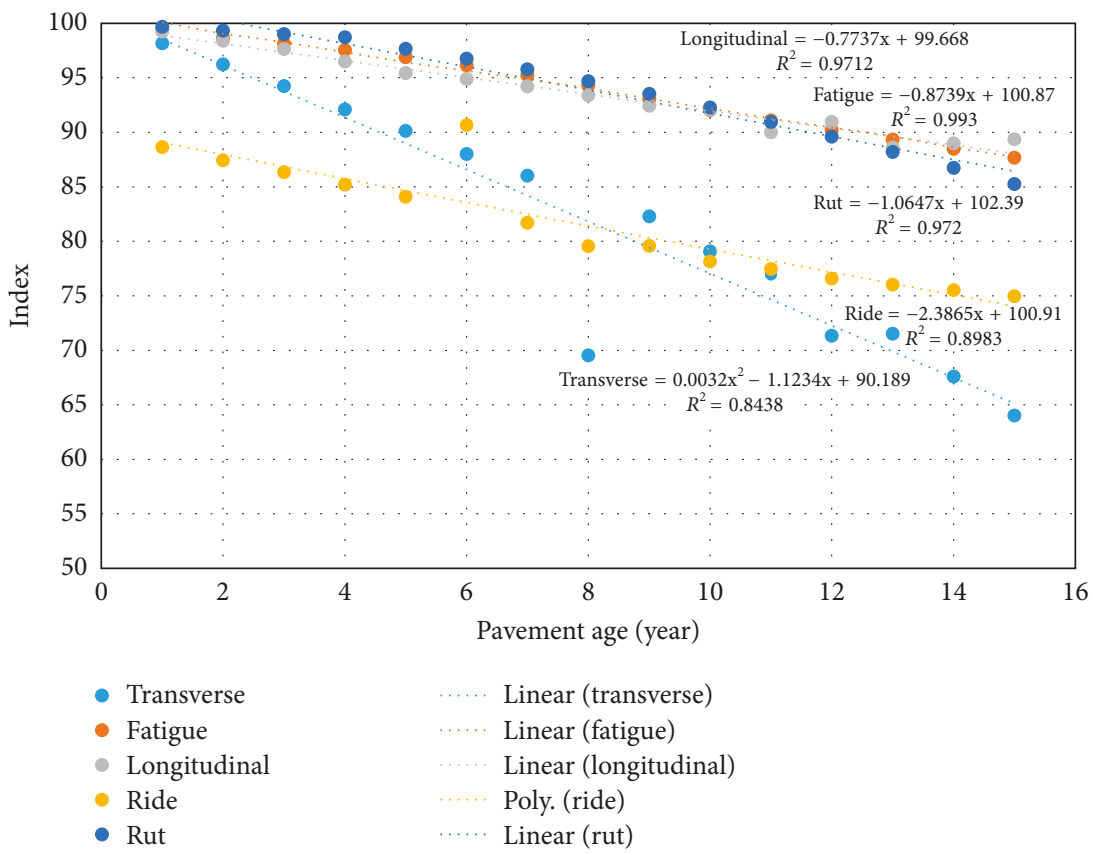

FIgURE 2: Deterioration models for transverse, longitudinal, fatigue, rut, and ride indices.

TABle 11: Probability distribution values from the transverse cracking index Markov model.

\begin{tabular}{ccccccc}
\hline & & Year 1 & Year 2 & Year 3 & Year 4 & Year 5 \\
\hline & 100 & $\mathbf{0 . 6 3 1}$ & 0.398 & 0.251 & 0.158 & 0.1 \\
Transverse cracking index & 95 & 0.369 & $\mathbf{0 . 4 5 1}$ & $\mathbf{0 . 4 1 3}$ & $\mathbf{0 . 3 3 6}$ & 0.257 \\
& 90 & 0 & 0.151 & 0.267 & 0.314 & $\mathbf{0 . 3 0 8}$ \\
& 85 & 0 & 0 & 0.069 & 0.167 \\
& 80 & 0 & 0 & 0 & 0.024 \\
& 75 & 0 & 0 & 0 & 0.072 \\
\hline
\end{tabular}

year and the remaining percentage (0.369) deteriorate from 100 to 95 the next year. Table 11 represents the probability distribution using the Markovian probability process. In this table, the state of the maximum probability is shown in the bold font. For example, at year 5, there is a probability of 0.1 for the segments to stay at 100 and a probability of 0.011 for the segments at 75, but the highest probability value is 0.308 at 90 .

Table 8 shows the probability matrices for all five distress indices, and Figure 2 shows the deterioration models. Deterioration models indicate that fatigue, rut, and longitudinal indices have very slow deterioration over the years. The other two indices transverse and ride are deteriorating faster. Regression techniques have been used to develop models using the mean obtained from the Markovian distribution. Equations (5)-(9) are the deterioration models for each distress.

$$
\begin{array}{r}
\text { Transverse }=-0.0032 * \text { Age }^{2}-1.1234 * \text { Age } \\
+90.189, \quad R^{2}=0.84
\end{array}
$$

Longitudinal $=-0.7737 *$ Age $+99.668, \quad R^{2}=0.97$, 


$$
\begin{aligned}
\text { Ride } & =-2.3865 * \text { Age }+100.91, \quad R^{2}=0.90, \\
\text { Rut } & =-0.7737 * \text { Age }+99.67, \quad R^{2}=0.97, \\
\text { Fatigue }=-1.0647 * \text { Age }+102.39, & R^{2}=0.97,
\end{aligned}
$$

where age indicates the age of the pavement after last rehabilitation.

\section{Conclusions}

In the state of Colorado, the CDOT utilizes their PMS to keep track of approximately 9,100 miles of interstate, highways, and low-volume roads. Three types of deterioration curves are used in their PMS: site-specific, family, and expert opinion curves. These curves are developed using deterministic techniques. Within the deterministic technique, the uncertainties of pavement deterioration related to traffic and weather are not considered. Probabilistic models that take into account the uncertainties result in more accurate curves. In this research, probabilistic models have been developed for five distress indices: transverse, longitudinal, fatigue, rut, and ride indices, as a case study on low-volume roads. Deterioration models were developed for 15 years to investigate the deterioration in long-term durations. As probabilistic models provide more accurate results, it is recommended that these models be used as the family curves in the CDOT PMS after minor modifications.

The developed models can be highlighted as follows:

(1) Tailored specifically to low-volume roads.

(2) As this methodology incorporates uncertainties, the developed models' results are more accurate than those currently used by the deterministic technique.

(3) This methodology can also be implemented on other functional classes of roadways in Colorado and for other states with minor changes that reflect local conditions.

\section{Recommendations}

DOTs are always shifting practices to better optimize limited resources. It was demonstrated in this paper that the deterioration models using the Markovian probability process can help DOTs better manage their pavements. It is recommended that a comprehensive study be conducted to determine the long-term implications of replacing deterministic models with Markov models in the state of Colorado. It is also recommended that other DOTs consider Markov probability processes when it comes to allocating resources or comparing maintenance and rehabilitation strategies within their jurisdictions.

\section{Conflicts of Interest}

The authors declare that there are no conflicts of interest regarding the publication of this paper.

\section{Acknowledgments}

The authors would like to thank the CDOT for supporting this research study.

\section{References}

[1] CDOT, "Proposed budget allocation plan," 2015, https://www. codot.gov/business/budget/cdot-budget/draft-budget-documents/ fy-2015-2016-cdot-proposed-narrative-budget/view.

[2] M. Keleman, S. Henry, A. Farrokhyar, and C. Stewart, Pavement Management Manual, Colorado Department of Transportation, Denver, CO, USA, 2005.

[3] L. Redd, CDOT's Risk-Based Asset Management Plan, Colorado Department of Transportation, Denver, CO, USA, 2013.

[4] CDOT, "Pavement management manual," 2008, https://www. codot.gov/content/projects/I-70-East-Draft-4/Schedule\%2029/ Schedule\%2011\%20-\%20Operations\%20and\%20Maintenance/29. 11.04\%20CDOT\%20Pavement\%20Management\%20Manual.pdf.

[5] F. Silva, T. Van Dam, W. Bulleit, and R. Ylitalo, "Proposed pavement performance models for local government agencies in Michigan," Transportation Research Record: Journal of the Transportation Research Board, vol. 1699, pp. 81-86, 2000.

[6] K. Surendrakumar, N. Prashant, and P. Mayuresh, "Application of Markovian probabilistic process to develop a decision support system for pavement maintenance management," International Journal of Scientific and Technology Research, vol. 2, no. 8, pp. 225-303, 2013.

[7] A. A. Butt, M. Y. Shahin, S. H. Carpenter, and J. V. Carnahan, "Application of Markov process to pavement management at network level," in Proceedings of $3 \mathrm{rd}$ International Conference on Managing Pavements, San Antonio, TX, USA, 1994.

[8] A. A. Butt, "Application of Markov process to pavement management systems at the network level," Ph.D. thesis, University of Illinois at Urbana-Champaign, Champaign, IL, USA, 1991.

[9] W. H. Kuo, Pavement Performance Models for Pavement Management System of Michigan Department of Transportation, Michigan Department of Transportation, Lansing, MI, USA, 1995.

[10] S. Akyildiz, "Development of new network-level optimization model for Salem district pavement management programming," M.S. thesis, Virginia Tech, Blacksburg, VA, USA, 2008.

[11] M. Y. Shahin, Pavement Management for Airports, Roads and Parking Lots, Chapman \& Hall, New York, NY, USA, 1994.

[12] N. Li, R. Haas, and W. C. Xie, "Investigation of relationships between deterministic and probabilistic prediction models in pavement management," Transportation Research Record: A Journal of Transportation Research Board, vol. 1592, pp. 70-79, 1997.

[13] J. M. de la Garza, S. Akyildiz, D. R. Bish, and D. A. Krueger, "Development of network-level linear programming optimization for pavement maintenance programming," in Proceedings of the International Conference on Computing in Civil and Building Engineering, Nottingham, UK, 2010.

[14] K. A. Abaza, "Expected performance of pavement repair works in a global network optimization model," Journal of Infrastructure Systems, vol. 13, no. 2, pp. 124-134, 2007. 
[15] A. Bako, E. Klafszky, T. Szantai, and L. Gaspar, "Optimization techniques for planning highway pavement improvements," Annals of Operations Research, vol. 58, no. 1, pp. 55-66, 1995.

[16] X. Chen, S. Hudson, M. Pajoh, and W. Dickinson, "Development of new network optimization model for Oklahoma Department of Transportation," Transportation Research Record: Journal of the Transportation Research Board, vol. 1524, pp. 103-108, 1996.

[17] K. Golabi, R. B. Kulkarni, and G. B. Way, "A statewide pavement management system," Interfaces, vol. 12, no. 6, pp. 5-21, 1982.

[18] K. A. Abaza, "Back-calculation of transition probabilities for Markovian-based pavement performance prediction models," International Journal of Pavement Engineering, vol. 17, no. 3, pp. 253-264, 2016. 


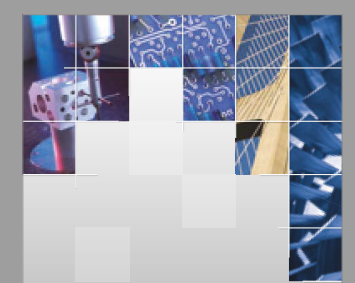

\section{Enfincering}
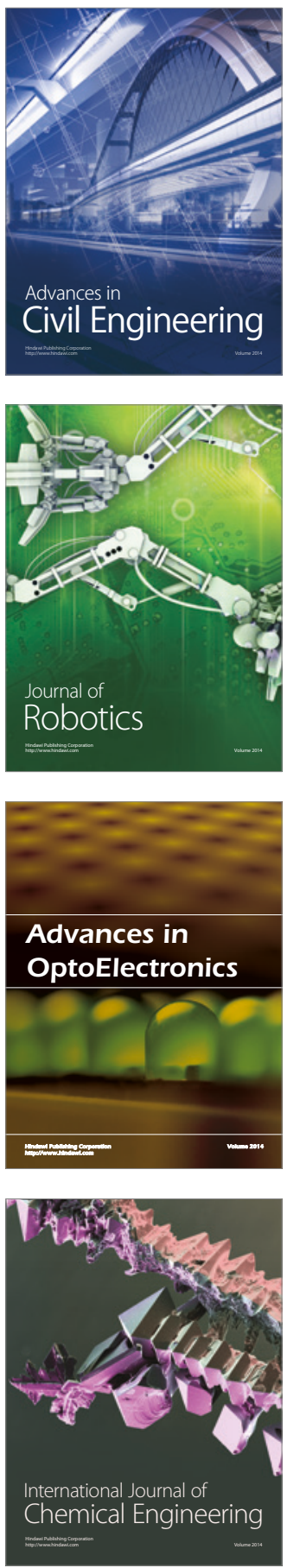

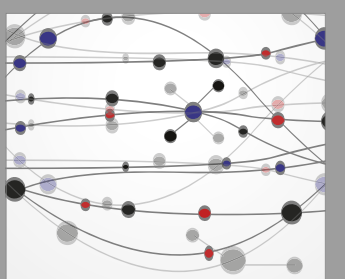

The Scientific World Journal

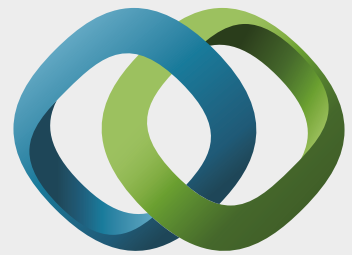

\section{Hindawi}

Submit your manuscripts at

https://www.hindawi.com
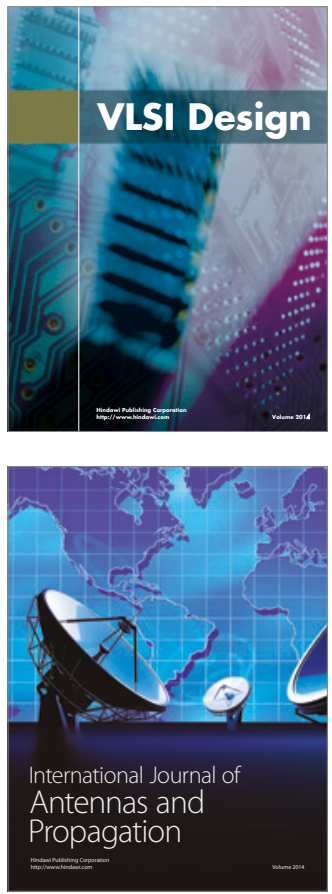

\section{Rotating}

Machinery
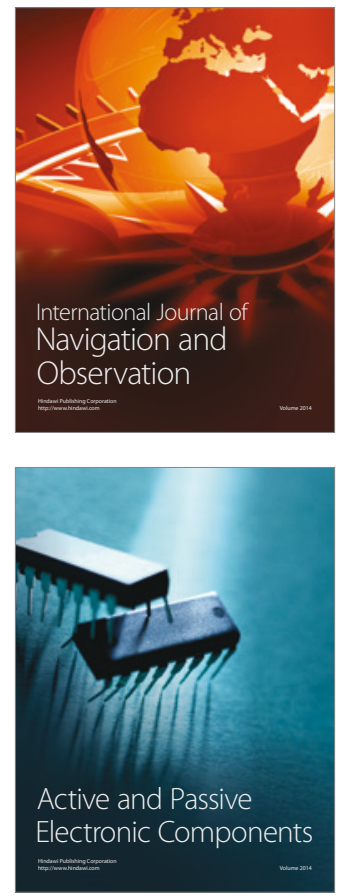
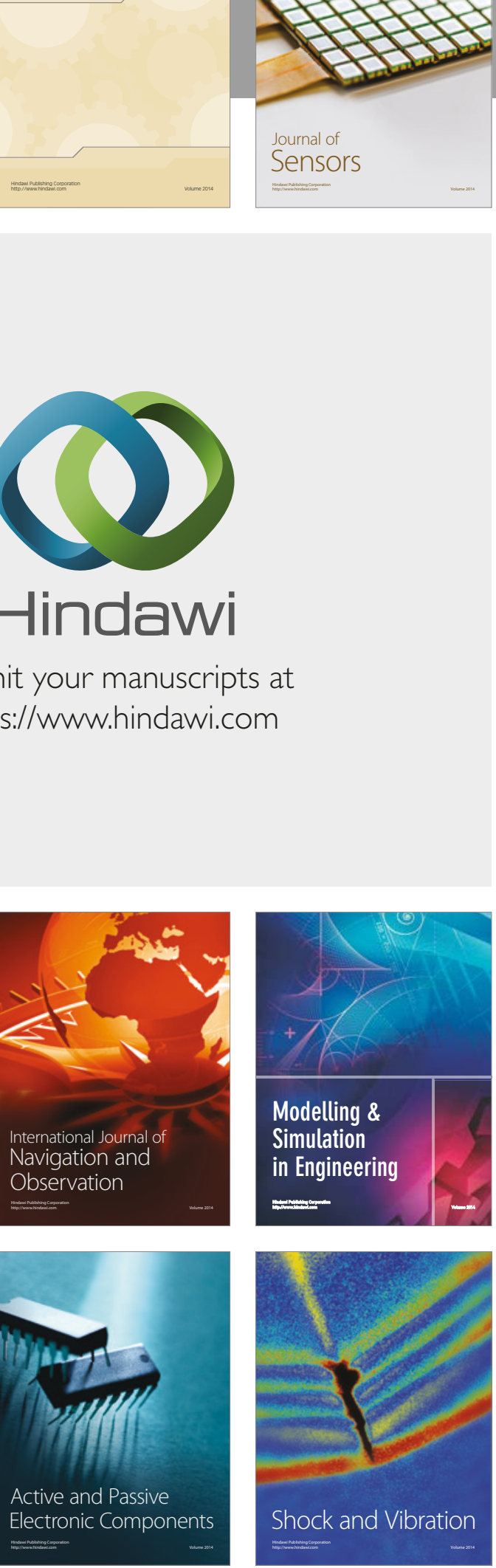
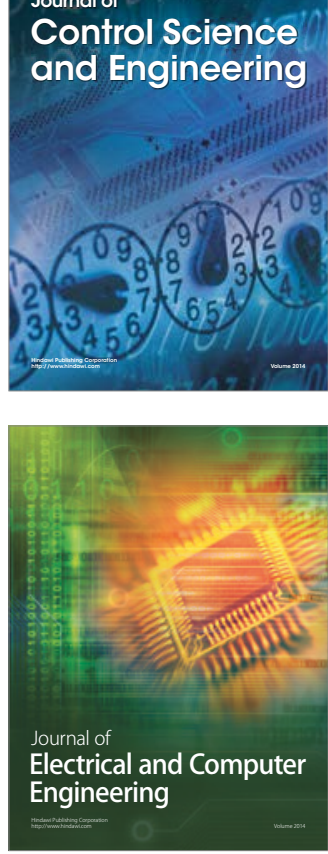

Distributed

Journal of

Control Science

and Engineering
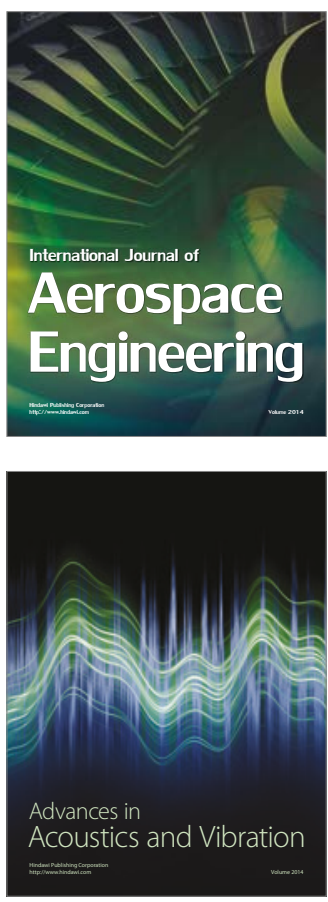

Sensor Networks 